\title{
Localisation and composition of skeletal muscle diacylglycerol predicts insulin resistance in humans
}

\author{
B. C. Bergman • D. M. Hunerdosse • A. Kerege • M. C. Playdon • L. Perreault
}

Received: 3 October 2011 / Accepted: 21 November 2011 /Published online: 15 January 2012

(C) Springer-Verlag 2012

\begin{abstract}
Aims/hypothesis We sought to evaluate if the cellular localisation and molecular species of diacylglycerol (DAG) were related to insulin sensitivity in human skeletal muscle.

Methods Healthy sedentary obese controls $(\mathrm{Ob} ; n=6$; mean \pm SEM age $39.5 \pm 2.3$ years; mean \pm SEM BMI $33.3 \pm$ $1.4 \mathrm{~kg} / \mathrm{m}^{2}$ ), individuals with type 2 diabetes (T2D; $n=6$; age $44 \pm 1.8$ years; BMI $30.1 \pm 2.3 \mathrm{~kg} / \mathrm{m}^{2}$ ), and lean endurancetrained athletes (Ath; $n=10$; age $35.4 \pm 3.1$ years; BMI $23.3 \pm$ $0.8 \mathrm{~kg} / \mathrm{m}^{2}$ ) were studied. Insulin sensitivity was determined using an IVGTT. Muscle biopsy specimens were taken after an overnight fast, fractionated using ultracentrifugation, and DAG species measured using liquid chromatography/MS/MS. Results Total muscle DAG concentration was higher in the $\mathrm{Ob}$ (mean $\pm \mathrm{SEM} 13.3 \pm 1.0 \mathrm{pmol} / \mu \mathrm{g}$ protein) and T2D (15.2 \pm $1.0 \mathrm{pmol} / \mu \mathrm{g}$ protein) groups than the Ath group (10.0土 $0.78 \mathrm{pmol} / \mu \mathrm{g}$ protein, $p=0.002)$. The majority $(76-86 \%)$ DAG was localised in the membrane fraction for all groups, but was lowest in the Ath group (Ob, $86.2 \pm 0.98 \%$; T2D, $84.2 \pm 1.2 \%$; Ath, $75.9 \pm 2.7 \%$; $p=0.008)$. There were no differences in cytoplasmic DAG species $(p>0.12)$. Membrane DAG species C18:0/C20:4, Di-C16:0 and Di-C18:0 were significantly more abundant in the T2D group. Cytosolic DAG species were negatively related to activation of protein kinase $\mathrm{C}(\mathrm{PKC}) \varepsilon$ but not $\mathrm{PKC} \theta$, whereas membrane DAG species were positively related to activation of $\mathrm{PKC} \varepsilon$, but not PKC $\theta$. Only total membrane DAG $(r=-0.624, p=0.003)$ and
\end{abstract}

B. C. Bergman $(\bowtie) \cdot$ D. M. Hunerdosse $\cdot$ A. Kerege $\cdot$

M. C. Playdon $\cdot$ L. Perreault

Division of Endocrinology, Metabolism, and Diabetes,

University of Colorado Anschutz Medical Campus,

12801 E. 17th Ave, PO Box 6511, MS 8106, Aurora,

CO 80045, USA

e-mail: Bryan.Bergman@ucdenver.edu
Di-C18:0 $(r=-0.595, p=0.004)$ correlated with insulin sensitivity. Disaturated DAG species were significantly lower in the Ath group $(p=0.001)$, and significantly related to insulin sensitivity $(r=-0.642, p=0.002)$.

Conclusions/interpretation These data indicate that both cellular localisation and composition of DAG influence the relationship to insulin sensitivity. Our results suggest that only saturated DAG in skeletal muscle membranes are related to insulin resistance in humans.

Keywords Athlete's paradox · Diacylglycerol .

Intramuscular lipid · Lipid composition · Protein kinase C

$\begin{array}{ll}\text { Abbreviations } \\ \text { Ath } & \text { Endurance-trained athletes } \\ \text { DAG } & \text { Diacylglycerol } \\ \text { DEXA } & \text { Dual-energy X-ray absorptiometry } \\ \text { DGAT1 } & \text { Diacylglycerol acyltransferase 1 } \\ \text { DGK } \delta & \text { Diacylglycerol kinase delta } \\ \text { GCRC } & \text { General Clinical Research Center } \\ \text { IMTG } & \text { Intramuscular triacylglycerol } \\ \text { Ob } & \text { Obese controls } \\ \text { PKC } & \text { Protein kinase C } \\ \text { SCD1 } & \text { Stearoyl-CoA desaturase 1 } \\ \text { T2D } & \text { Individuals with type 2 diabetes } \\ \dot{V} \mathrm{O}_{2 \max } & \text { Maximal oxygen consumption }\end{array}$

\section{Introduction}

As the epidemic of type 2 diabetes continues to grow, exploitation of new targets for diabetes prevention and treatment has become critical. Targets in skeletal muscle may hold particular promise in this regard. Skeletal muscle is the major tissue responsible for insulin action on peripheral 
glucose uptake, and therefore has been implicated as a primary site for the development of insulin resistance and type 2 diabetes [1]. Nevertheless, known mechanisms of insulin resistance in muscle have failed to render new therapeutic targets. For example, considerable attention has been paid to the association between intramuscular triacylglycerol (IMTG) concentration and muscle insulin resistance despite consensus that IMTG itself probably does not cause insulin resistance. Further, increasing evidence suggests that IMTG concentration and insulin action may be dissociated [2, 3]. Importantly, however, emerging data from our laboratory and others suggest that intramuscular lipid composition, rather than concentration, may play an important role [4-7].

There are several lipid molecules that may influence muscle insulin sensitivity, including long-chain acyl-CoA [8], ceramides $[9,10]$ and diacylglycerol (DAG) [11-14]. This study focused on intramuscular DAG, which is created in the synthesis and degradation of IMTG as well as from degradation of phospholipids. DAG contributes only a small fraction of the total intramuscular lipid pool, but has potent biological effects. Specifically, increased skeletal muscle DAG concentration and insulin resistance have been reported in animal models [11-13] and humans [14], presumably from its ability to activate protein kinase $\mathrm{C}$ (PKC) $[11,14,15]$. To date, DAG has been universally viewed as having a negative effect on muscle insulin action. If one considers that DAG consists of two fatty acids bound mainly on the first and second carbons of glycerol, many possible species of DAG exist, each with potential for unique biological action. Previous data from our laboratory showed that DAGs comprised of saturated fatty acids were related to insulin resistance in younger people [4], and this was particularly evident in highly insulinsensitive endurance-trained athletes, who had lower DAG saturation [5]. Although not universally observed [10], corroborative data in both cells [16] and humans [6, 7] support this notion. Altogether, there is reason to believe that DAG composition in skeletal muscle deserves closer attention. Our aim was to determine if all DAG molecular species are equally deleterious to insulin sensitivity.

Notably, in addition to composition, the insulin-desensitising effects of DAG may be governed by its subcellular location [17]. The vast majority of studies published in humans report total skeletal muscle DAG concentration, without measuring compartmentalisation within the cell. Since the adverse effects of PKC are confined to cell membranes, it is likely that only DAGs located in certain compartments influence PKC activation and insulin sensitivity. We hypothesised that changes in DAG molecular species and localisation influence PKC activation and insulin action, and may help explain differences in insulin sensitivity between individuals.

\section{Methods}

Participants Six obese sedentary controls $(\mathrm{Ob})$, six individuals with type 2 diabetes (T2D), and ten endurance-trained athletes (Ath) were recruited for this study. They gave written informed consent, and were excluded if they had a BMI $<20$ or $>25 \mathrm{~kg} / \mathrm{m}^{2}$ for Ath, and BMI $<28$ or $>40 \mathrm{~kg} / \mathrm{m}^{2}$ for Ob and T2D. Participants were excluded if they had fasting triacylglycerol concentration $>1.7 \mathrm{mmol} / \mathrm{l}$ or liver, kidney, thyroid or lung disease. Sedentary controls were engaged in planned physical activity $<2 \mathrm{~h} /$ week. Ath were competitive cyclists, triathletes and runners with mean \pm SEM lactate thresholds of $81 \pm 2.6 \%$ of maximal oxygen consumption $\left(\dot{V} \mathrm{O}_{2 \max }\right)$, and had been training on average $15.6 \pm 1.5 \mathrm{~h} /$ week for the past $9.6 \pm$ 2.2 years for the purpose of competition. The T2D individuals were included in the study if they did not take insulin and/or thiazoladinediones. All other glucose-lowering medications were washed out for 2 weeks before metabolic testing. Controls and athletes were not taking medications. Participants were weight stable in the 6 months before the study. This study was approved by the Colorado Multiple Institution Review Board at the University of Colorado Denver.

Preliminary testing Participants reported to the General Clinical Research Center (GCRC) for screening procedures after a $12 \mathrm{~h}$ overnight fast, where they were given a health and physical examination, followed by a fasting blood draw. Body composition was determined using dual-energy $\mathrm{x}$-ray absorptiometry (DEXA) analysis (Lunar DPX-IQ, Lunar Corporation, Madison, WI, USA).

Insulin sensitivity Insulin sensitivity was determined via an IVGTT using standard methods after an overnight fast [18]. Briefly, after baseline samples had been taken, intravenous glucose $(0.3 \mathrm{~g} / \mathrm{kg})$ was infused over $1 \mathrm{~min}$, followed by insulin at $0.03 \mathrm{U} / \mathrm{kg}, 20 \mathrm{~min}$ after glucose administration. Blood samples were then frequently sampled over $3 \mathrm{~h}$, and wholebody insulin sensitivity was calculated using the Bergman minimal model [18] (Millennium Version, MINMOD, Los Angeles, CA, USA).

Diet and exercise control All participants were given a prescribed diet for 3 days before admission to the GCRC. Daily energy requirement was estimated from the DEXA measurement of fat free mass (FFM) using the equation: daily energy intake $=5.86 \mathrm{~kJ}(1.4 \mathrm{kcal}) /$ day $\times$ $[372+(23.9 \times \mathrm{FFM})]$, and analysis of dietary records. The composition of this diet was $55 \%$ carbohydrate, $30 \%$ fat and $15 \%$ protein. The fat content of the diet was controlled with the composition of saturated, monounsaturated and polyunsaturated fat in a 1:1:1 ratio. Participants were asked to refrain from planned physical activity for $48 \mathrm{~h}$ before the muscle biopsy study. 
Table 1 Participants' demographics

Values are means \pm SEM

${ }^{\mathrm{a}}$ To convert values to SI units multiply by 0.167

Significantly different from obese, $* p<0.05$; significantly different from $\mathrm{T} 2 \mathrm{D},{ }^{\dagger} p<0.05$; significantly different from athletes, ${ }^{\star} p<0.05$

\begin{tabular}{|c|c|c|c|}
\hline Variable & Obese & $\mathrm{T} 2 \mathrm{D}$ & Athletes \\
\hline Number (female/male) & $6(2 / 4)$ & $6(0 / 6)$ & $10(2 / 8)$ \\
\hline Age (years) & $39.5 \pm 2.3$ & $44 \pm 1.8$ & $35.4 \pm 3.1$ \\
\hline $\operatorname{BMI}\left(\mathrm{kg} / \mathrm{m}^{2}\right)$ & $33.3 \pm 1.4$ & $30.1 \pm 2.3$ & $23.3 \pm 0.8^{* \dagger}$ \\
\hline Body fat $(\%)$ & $34.1 \pm 4.5$ & $30.7 \pm 2.8$ & $14.1 \pm 2.2 *{ }^{\dagger}$ \\
\hline$\dot{V} \mathrm{O}_{2 \max }\left(\mathrm{ml} \mathrm{kg}^{-1} \min ^{-1}\right)$ & $25.1 \pm 3.9$ & $25.4 \pm 1.8$ & $55.6 \pm 4.8^{* \dagger}$ \\
\hline $\mathrm{HbA}_{1 \mathrm{c}}$ (proportion of total) & $0.055 \pm 0.001$ & $0.071 \pm 0.005^{*}$ & $0.055 \pm 0.001$ \\
\hline $\mathrm{HbA}_{1 \mathrm{c}}(\mathrm{mmol} / \mathrm{mol})$ & $36.2 \pm 0.9$ & $54.3 \pm 3.6^{* \ddagger}$ & $36.6 \pm 0.4$ \\
\hline Fasting glucose $(\mathrm{mmol} / \mathrm{l})$ & $5.4 \pm 0.2$ & $7.7 \pm 1.3^{*}$ & $4.4 \pm 0.2$ \\
\hline Fasting insulin (pmol/l) & $52.1 \pm 13.2$ & $140.3 \pm 30.6^{* \star}$ & $24.3 \pm 2.8$ \\
\hline Fasting NEFA (umol/1) & $716 \pm 68$ & $589 \pm 87$ & $678 \pm 47$ \\
\hline Insulin sensitivity $\left(10^{-4} \mu \mathrm{U}^{-1} \mathrm{ml}^{-1}\right)^{\mathrm{a}}$ & $3.2 \pm 0.4$ & $2.4 \pm 0.6$ & $12.6 \pm 1.7^{* \dagger}$ \\
\hline
\end{tabular}

Muscle biopsy Participants arrived in the morning after a $12 \mathrm{~h}$ overnight fast. After $4 \mathrm{~h}$ of rest, muscle biopsy samples were taken from midway between the greater trochanter of the femur and patella. The anatomic location and depth of the biopsy was as similar as possible between participants to minimise variance in muscle fibre composition, which varies with depth and length in the vastus lateralis. Muscle was immediately flash frozen in liquid nitrogen and stored at $-80^{\circ} \mathrm{C}$ until dissection and analysis. Skeletal muscle samples were dissected free of extramuscular fat on ice as previously described [19].

Cell fractionation The membrane and cytosolic fractions were isolated using a well-accepted ultracentrifugation protocol, which has already been described [11]. Briefly, muscle biopsy specimens ( 40-50 mg wet weight) were extracted in ice-cold homogenising buffer A $(20 \mathrm{mmol} / \mathrm{l}$ 3-( $N$-morpholino)propanesulfonic acid (MOPS), $\mathrm{pH} 7.5$, $250 \mathrm{mmol} / \mathrm{lmannitol}, 1.2 \mathrm{mmol} / \mathrm{l} \mathrm{EGTA}, 1 \mathrm{mmol} / \mathrm{l}$ dithiothreitol, $2 \mathrm{mmol} / 1$ phenylmethylsulfonyl fluoride [PMSF], protease [Roche Applied Science, Indianapolis, IN, USA] and phosphatase inhibitors [Sigma, St Louis, MO, USA]) at $4^{\circ} \mathrm{C}$. The homogenate was centrifuged at $100,000 \mathrm{~g}$ for $45 \mathrm{~min}$, and the supernatant fraction, representing the cytosolic fraction, removed and stored in liquid nitrogen. The $100,000 \mathrm{~g}$ pellet was washed once by resuspension in homogenising buffer $\mathrm{A}$ and re-centrifuged, and the protein pellet solubilised in homogenising buffer B ( $20 \mathrm{mmol} / 1 \mathrm{MOPS}$, $\mathrm{pH} 7.5,0.5 \%$ decanoyl- $N$-methyl-glucamide, $2 \mathrm{mmol} / \mathrm{l}$ EDTA, $5 \mathrm{mmol} / 1 \mathrm{EGTA}, 1 \mathrm{mmol} / 1$ dithiothreitol, $2 \mathrm{mmol} / \mathrm{l} \mathrm{PMSF}$, protease and phosphatase inhibitors). After $1 \mathrm{~h}$ at $4^{\circ} \mathrm{C}$ with constant gentle inversion, the extract was centrifuged again at $100,000 \mathrm{~g}$ for $45 \mathrm{~min}$, and the supernatant fraction saved, representing the membrane fraction.

Liquid chromatography/tandem MS Isolated cell fractions were shipped frozen on dry ice overnight to the Medical
University of South Carolina lipidomics laboratory for analysis. In the lipidomics laboratory, samples were fortified with internal standards, extracted into a one-phase neutral organic solvent system, and analysed by a Thermo Finnegan TSQ 7000 triple quadrupole mass spectrometer as previously described [20]. Examination of DAG molecular species was performed by a parent ion scan of a common fragment ion characteristic of each class of lipid. Concentration was determined by comparing ratios of unknowns with internal standards, and referencing a standard curve.

Western blotting To determine PKC activation and enrichment of membrane and cytosolic fractions, $15 \mu \mathrm{g}$ of sample protein from membrane and cytosolic fractions were run on an SDSPAGE $8 \%$ Bis-Tris gel (Invitrogen, Carlsbad, CA, USA), then transferred to a poly(vinylidene difluoride) membrane, and blocked with $5 \%$ BSA for $1 \mathrm{~h}$ at room temperature. Primary antibodies were from Cell Signaling (Danvers, MA, USA). Incubations were performed in $5 \% \mathrm{BSA}$ overnight at $4{ }^{\circ} \mathrm{C}$, and a horseradish peroxidase-conjugated secondary antibody was incubated for $1 \mathrm{~h}$ at room temperature. Enhanced chemiluminescence was used to visualise protein bands of interest. Intensity of protein bands was captured using an

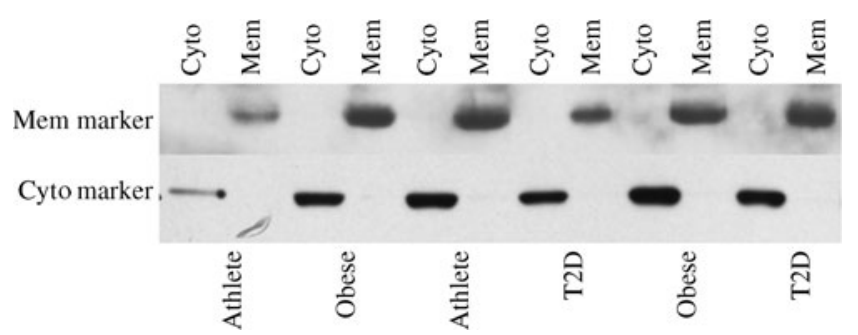

Fig. 1 Western blot showing enrichment of membrane and cytosolic proteins in human skeletal muscle biopsy specimens separated by ultracentrifugation. The membrane marker antibody is $\mathrm{Na} / \mathrm{K}$ ATPase $\alpha 1$, and the cytosolic marker is glyceraldehyde-3-phosphate dehydrogenase. Cyto, cytosol; Mem, membrane; T2D, type 2 diabetes 

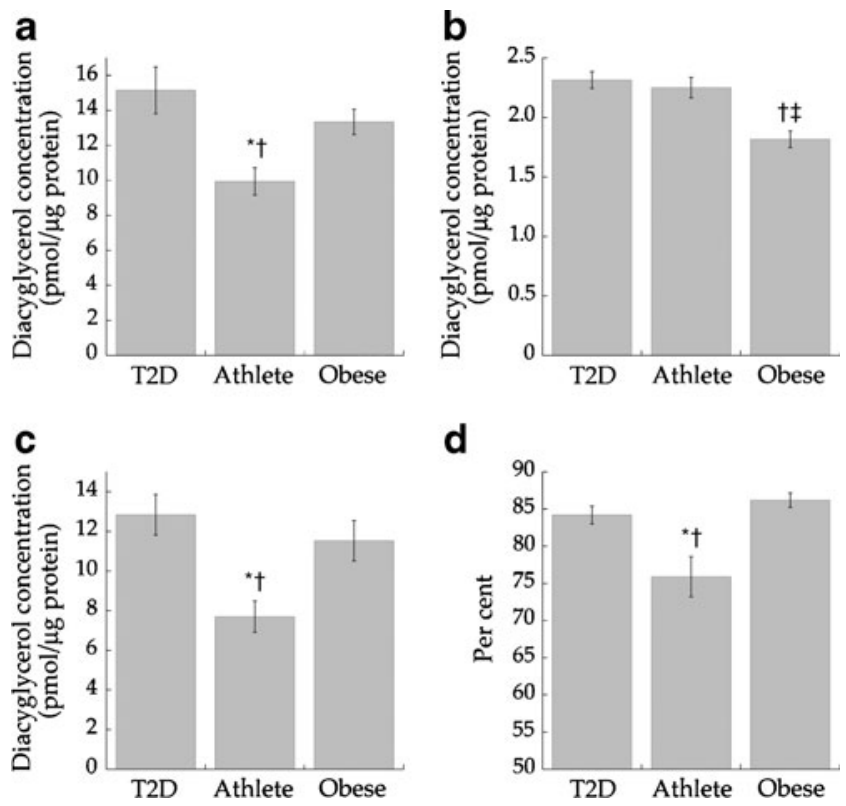

Fig. 2 DAG concentration by group in total muscle homogenate (a), cytosolic fraction (b) and membrane fraction (c) and percentage DAG in membrane fraction (d). Values are means \pm SEM. Significantly different from $\mathrm{Ob},{ }^{*} p<0.05$; significantly different from $\mathrm{T} 2 \mathrm{D},{ }^{\dagger} p<0.05$; significantly different from Ath, ${ }^{\star} p<0.05$. T2D, type 2 diabetes

AlphaImager 3300 and quantified using FluorChem software (Alpha Innotech Corp, San Leandro, CA, USA).

Statistical analysis Data are presented as mean \pm SEM. Differences in normally distributed data between groups were analysed using a one-way ANOVA (SPSS, Chicago, IL, USA). Non-normally distributed data were log transformed before analysis using a one-way ANOVA. When significant differences were detected, individual means were compared using Student's $t$ tests to determine differences between groups. An alpha level of 0.05 was used for statistical significance other than comparisons with multiple DAG species. For evaluation of statistical significance with multiple DAG species, the Bonferroni method was used to correct for 16 multiple comparisons, leaving a significant $p$ value that had to be $<0.0031$. Relationships between DAG molecular species, insulin sensitivity and PKC activation were determined using Pearson's correlation coefficient.

\section{Results}

Demographic information for participants is shown in Table 1. As expected, the $\mathrm{Ob}$ and $\mathrm{T} 2 \mathrm{D}$ groups had higher BMI and percentage body fat than the Ath group, and the $\dot{V} \mathrm{O}_{2 \max }$ of the Ath group was more than twice that of the $\mathrm{Ob}$ and T2D groups. As expected $\mathrm{HbA}_{1 \mathrm{c}}$, fasting glucose and insulin levels were significantly higher in the T2D group than the other two groups. Insulin sensitivity was significantly greater in the Ath group than the $\mathrm{Ob}$ and $\mathrm{T} 2 \mathrm{D}$ groups.

Skeletal muscle fractionation Enrichment of membrane and cytosolic markers in their respective subcellular compartments isolated by ultracentrifugation are shown in Fig. 1. These data show that the cellular fractionation methods were successful in enriching membrane and cytosolic proteins, and suggest minimal contamination between fractions.

Subcellular localisation of DAG The cellular distribution of skeletal muscle DAG is shown in Fig. 2. Total DAG concentration was significantly higher in the $\mathrm{Ob}$ and T2D groups than in the Ath group (Fig. 2a, $p=0.002$ ), commensurate with their greater insulin resistance. We found a significant inverse relationship between total muscle DAG concentration and insulin sensitivity $(r=-0.626, p=0.002)$. Cytosolic DAG concentration was significantly lower in the Ob group than the T2D and Ath groups (Fig. 2b, $p=0.009$ ). Most DAG was in the membrane in all groups, but both
Fig. 3 Relationship between insulin sensitivity $(\mathrm{Si})$ and total cytosolic DAG $(r=0.217$, $p=0.34$ ) (a) and total membrane DAG ( $r=-0.624, p=0.003)$ (b) in $\mathrm{T} 2 \mathrm{D}$, Ath and $\mathrm{Ob}$ groups. To convert Si values to SI units multiply by 0.167
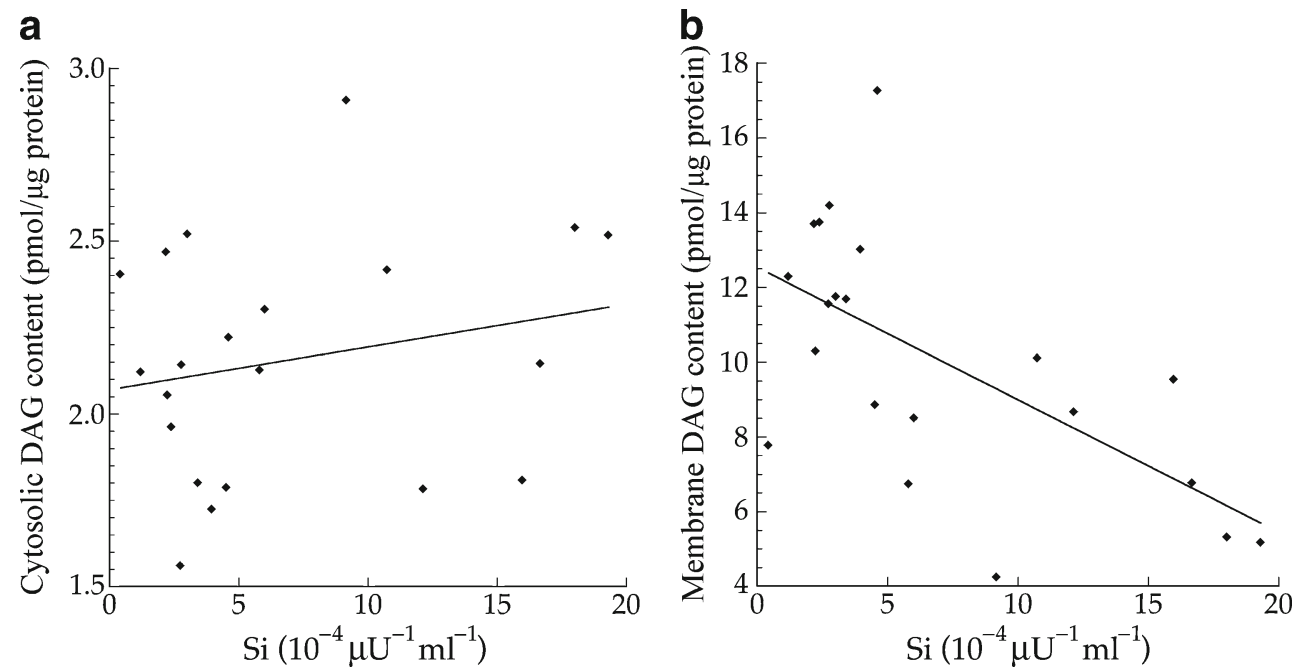
absolute (Fig. 2c, $p=0.002$ ) and percentage of total DAG concentration in membranes was lowest in the Ath group (Fig. 2d, $p=0.01$ ). Importantly, percentage of total DAG localised to membranes was significantly inversely related to insulin sensitivity $(r=-0.691, p=0.0005)$. There was no relationship between cytosolic DAG and insulin sensitivity (Fig. 3a, $p=0.34$ ), but a significant relationship between membrane DAG and insulin sensitivity was observed in the cohort as a whole (Fig. 3b, $r=-0.624, p=0.003$ ).

$D A G$ molecular species After correcting for multiple comparisons with Bonferroni, we found no significant relationships between individual DAG species in the whole cell and insulin sensitivity $(p>0.02)$. There were no significant
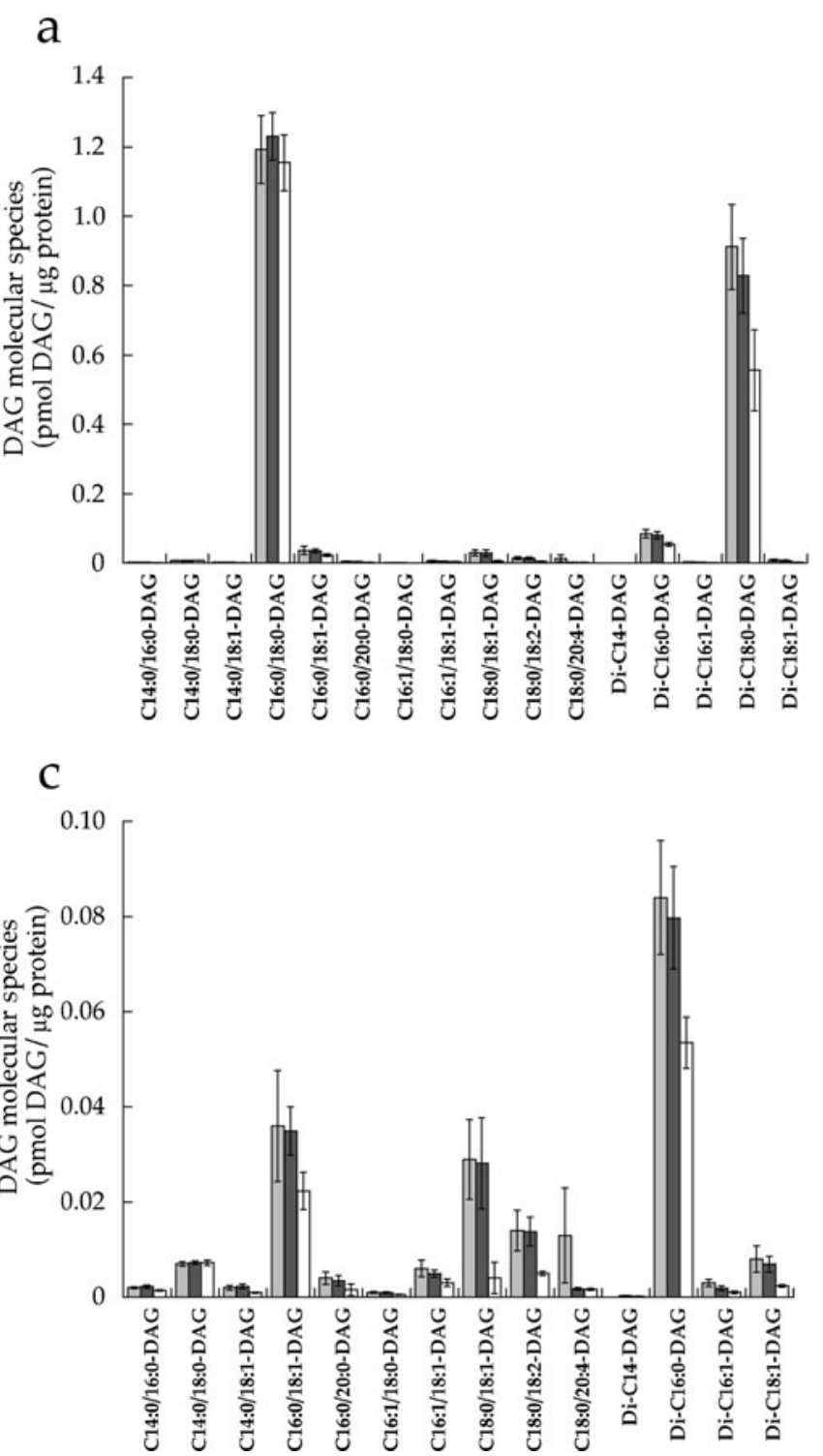

Fig. 4 DAG molecular species in T2D (light grey), Ath (dark grey) and $\mathrm{Ob}$ (white) groups localised in the cytosolic fraction (a) and membrane fraction (b), and low-abundance DAG species in the differences between groups for any cytosolic DAG species (Fig. 4a). However, the membrane DAG species, C18:0/ $\mathrm{C} 20: 4(p=0.0008)$, di-C16:0 $(p=0.004)$ and di-C18:0 $(p=$ $0.0005)$, were significantly higher in the $\mathrm{T} 2 \mathrm{D}$ group than the other two groups (Fig. 4b, d). Low-abundance cytosolic (Fig. 4c) and membrane (Fig. 4d) DAG species are shown in separate panels, with more abundant species removed in order to facilitate interpretation.

Data were combined from all groups and molecular species correlated by compartment with insulin sensitivity (Table 2). As with DAG species in the whole cell, there were no significant relationships between any DAG species in the cytosol and insulin sensitivity $(p>0.02)$. The only membrane DAG species that correlated with insulin sensitivity was

b

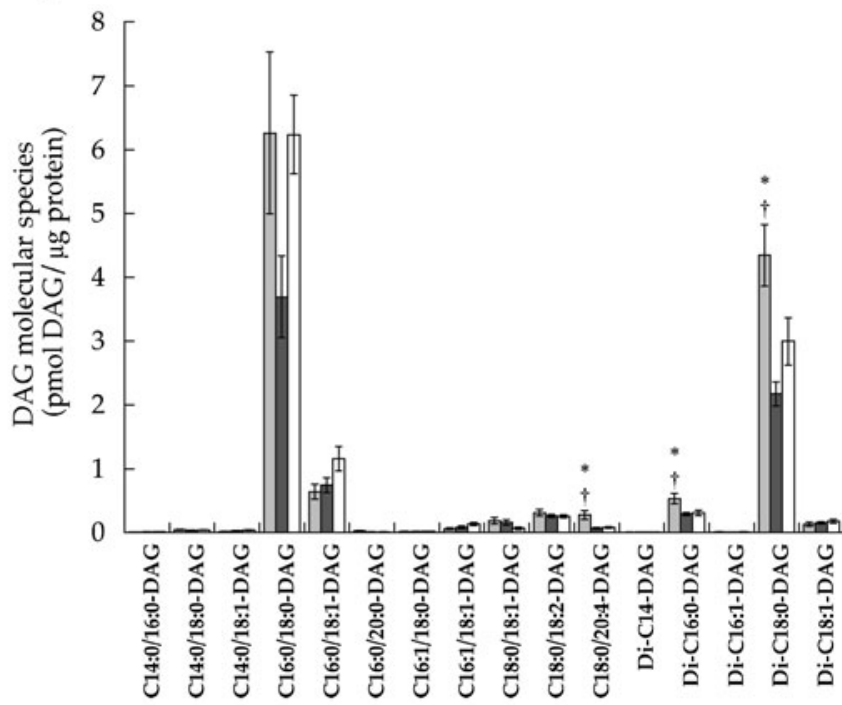

d

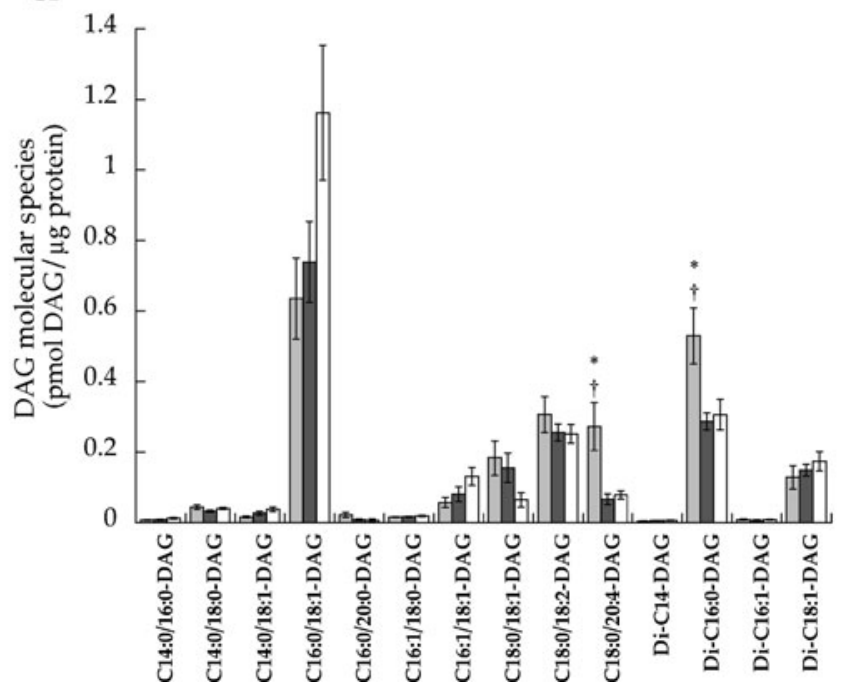

cytosolic fraction (c) and membrane fraction (d). Values are means \pm SEM. Significantly different from $\mathrm{Ob},{ }^{*} p<0.05$; significantly different from Ath, ${ }^{\dagger} p<0.05$ 
Table $2 p$ values and Pearson's correlation coefficients between DAG molecular species in cytosolic and membrane fractions and insulin sensitivity, and $\mathrm{PKC} \varepsilon$ and $\theta$ activation

\begin{tabular}{|c|c|c|c|c|c|c|}
\hline \multirow[t]{2}{*}{ DAG } & \multicolumn{2}{|c|}{ Insulin sensitivity } & \multicolumn{2}{|c|}{ PKC $\varepsilon$ activation } & \multicolumn{2}{|c|}{ PKC $\theta$ activation } \\
\hline & $p$ value & Correlation & $p$ value & Correlation & $p$ value & Correlation \\
\hline \multicolumn{7}{|l|}{ Cytosolic } \\
\hline C14:0/16:0-DAG & 0.123 & 0.347 & 0.019 & -0.508 & 0.747 & -0.073 \\
\hline C14:0/18:0-DAG & 0.389 & 0.198 & 0.549 & 0.139 & 0.047 & 0.429 \\
\hline C14:0/18:1-DAG & 0.023 & 0.495 & 0.097 & -0.371 & 0.668 & -0.097 \\
\hline C16:0/18:0-DAG & 0.953 & 0.014 & 0.165 & 0.314 & 0.191 & 0.290 \\
\hline C16:0/18:1-DAG & 0.247 & 0.264 & 0.926 & -0.022 & 0.302 & 0.231 \\
\hline C16:1/18:0-DAG & 0.207 & 0.287 & 0.027 & -0.483 & 0.563 & 0.130 \\
\hline C16:1/18:1-DAG & 0.742 & 0.077 & 0.991 & -0.003 & 0.275 & 0.243 \\
\hline C18:0/18:1-DAG & 0.124 & 0.347 & $0.0006^{\mathrm{a}}$ & -0.686 & 0.127 & -0.336 \\
\hline C18:0/18:2-DAG & 0.078 & 0.393 & 0.140 & -0.334 & 0.974 & -0.007 \\
\hline C18:0/20:4-DAG & 0.420 & -0.186 & 0.257 & 0.259 & 0.182 & 0.295 \\
\hline Di-C14:0-DAG & 0.070 & 0.403 & $0.003^{\mathrm{a}}$ & -0.616 & 0.806 & -0.056 \\
\hline Di-C16:0-DAG & 0.235 & 0.271 & $0.002^{\mathrm{a}}$ & -0.636 & 0.376 & -0.198 \\
\hline Di-C16:1-DAG & 0.909 & -0.027 & 0.010 & -0.546 & 0.943 & -0.016 \\
\hline Di-C18:0-DAG & 0.567 & 0.132 & $0.002^{\mathrm{a}}$ & -0.635 & 0.104 & -0.356 \\
\hline Di-C18:1-DAG & 0.201 & 0.291 & 0.198 & -0.293 & 0.913 & 0.025 \\
\hline \multicolumn{7}{|l|}{ Membrane } \\
\hline C14:0/16:0-DAG & 0.347 & -0.216 & 0.010 & 0.549 & 0.657 & -0.100 \\
\hline C14:0/18:0-DAG & 0.089 & -0.380 & 0.060 & 0.417 & 0.367 & 0.202 \\
\hline C14:0/18:1-DAG & 0.853 & -0.043 & 0.0187 & 0.508 & 0.680 & -0.093 \\
\hline C16:0/18:0-DAG & 0.027 & -0.483 & 0.014 & 0.529 & 0.061 & 0.406 \\
\hline C16:0/18:1-DAG & 0.578 & -0.129 & $0.002^{\mathrm{a}}$ & 0.628 & 0.311 & 0.226 \\
\hline C16:0/20:0-DAG & 0.318 & -0.229 & 0.218 & -0.281 & 0.372 & -0.200 \\
\hline C16:1/18:0-DAG & 0.932 & 0.020 & 0.131 & 0.341 & 0.416 & 0.183 \\
\hline C16:1/18:1-DAG & 0.539 & -0.142 & $0.0005^{\mathrm{a}}$ & 0.692 & 0.400 & 0.189 \\
\hline C18:0/18:1-DAG & 0.281 & 0.247 & 0.009 & -0.557 & 0.069 & -0.395 \\
\hline C18:0/18:2-DAG & 0.656 & 0.103 & 0.853 & 0.043 & 0.990 & -0.003 \\
\hline C18:0/20:4-DAG & 0.056 & -0.423 & 0.502 & 0.155 & 0.713 & 0.083 \\
\hline Di-C14:0-DAG & 0.715 & 0.085 & 0.401 & 0.193 & 0.696 & -0.088 \\
\hline Di-C16:0-DAG & 0.097 & -0.372 & 0.606 & -0.119 & 0.820 & -0.051 \\
\hline Di-C16:1-DAG & 0.049 & -0.433 & 0.188 & 0.299 & 0.591 & -0.121 \\
\hline Di-C18:0-DAG & $0.003^{\mathrm{a}}$ & -0.595 & 0.781 & 0.065 & 0.749 & 0.072 \\
\hline Di-C18:1-DAG & 0.753 & 0.073 & 0.020 & 0.503 & 0.438 & 0.174 \\
\hline
\end{tabular}

di-C18:0 $(r=-0.595, p=0.003)$, and appeared to be the species responsible for the significant overall relationship between membrane DAG and insulin sensitivity (Table 2).

Fasting glucose concentration was significantly positively related to both membrane DAG $(r=0.478, p=0.024)$ and total cell DAG $(r=0.496, p=0.019)$, but not cytosolic DAG $(r=$ $-0.023, p=0.92)$. There were no significant relationships between DAG and fasting insulin or NEFA concentrations.

$D A G$ and $P K C$ The ratio of membrane to cytosolic $\mathrm{PKC}$ content is a common surrogate for activation, since $\mathrm{PKC}$ is thought to be active in the membrane fraction only [21]. Although the data trended for lower $\mathrm{PKC} \varepsilon$ and $\mathrm{PKC} \theta$ activation in the Ath group compared with the T2D and $\mathrm{Ob}$ groups, the differences were not significant (Fig. 5a, b, $p=0.15)$. When analysed as continuous variables, cytosolic DAG concentration was negatively related to $\mathrm{PKC} \varepsilon$ activation (Fig. 6a, $r=-0.552, p=0.009$ ), whereas membrane DAG concentration was positively related to $\mathrm{PKC} \varepsilon$ (Fig. $6 \mathrm{~b}, r=0.507$, $p=0.019)$. We found that, in the cytosol, C18:0/C18:1 ( $p=$ $0.0006)$, di-C14:0 $(p=0.003)$, di-C16:0 $(p=0.002)$ and di-C18:0 $(p=0.002)$ were significantly inversely related to $\mathrm{PKC} \varepsilon$ activation (Table 2). No similar relationships were observed for PKC $\theta(p>0.05)$, suggesting PKC isoform specificity for particular DAG species. In the membrane, we found significant positive relationships between $\mathrm{PKC} \varepsilon$ activation 
a

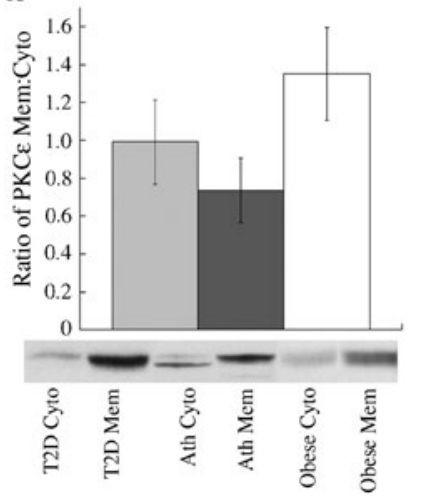

b

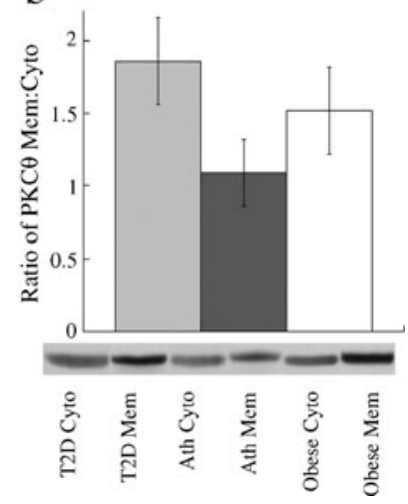

Fig. 5 Ratio of membrane (Mem) to cytosolic (Cyto) content of PKC $\varepsilon$ (a) and $\mathrm{PKC} \theta$ (b) in T2D (light grey), Ath (dark grey), and $\mathrm{Ob}$ (white) groups. Values are means \pm SEM

and $\mathrm{C} 16: 0 / \mathrm{C} 18: 1(p=0.002)$ and $\mathrm{C} 16: 1 / \mathrm{C} 18: 1 \quad(p=0.0005)$ (Table 2). No significant relationships were found for PKC $\theta$ $(p>0.06)$.

$D A G$ saturation and insulin sensitivity To determine if overall DAG saturation differed by group, we calculated the sum of DAG species with saturated acyl species on the first and second carbon. The concentration of total cell disaturated DAG $(p=0.001)$ and absolute membrane disaturated DAG content ( $p=0.001$, Fig. 7a) was significantly lower in the Ath group than the other two groups. The absolute content of membrane disaturated DAG was significantly negatively related to insulin sensitivity ( $r=-0.642, p=0.002$, Fig. $7 b$ ). The relative membrane disaturated DAG content was significantly lower in the Ath than the T2D group ( $p=0.03$, Fig. $7 \mathrm{c}$ ), and was significantly negatively related to insulin sensitivity $(r=-0.633$, $p=0.002$, Fig. $7 \mathrm{~d}$ ).

Muscle protein expression We analysed expression of enzymes involved in attenuating DAG signalling (diacylglycerol kinase $\delta[D G K \delta]$ ), triacylglycerol synthesis (diacylglycerol acyltransferase 1 [DGAT1] and lipin 1) and lipid desaturation (stearoylCoA desaturase 1 [SCD1]). Figure 8 shows no significant differences in protein content of whole cell DGK $\delta(p=0.71)$, DGAT1 $(p=0.88)$ or lipin $1(p=0.20)$ between groups. Only SCD1 content was different between groups, with significantly increased abundance in the Ath group compared with the $\mathrm{Ob}$ group $(p=0.03)$.

\section{Discussion}

Strong evidence suggests that DAG may be an important link between tissue lipids and insulin resistance. Skeletal muscle DAG concentration is elevated in individuals with obesity and type 2 diabetes [22], and has been shown to be negatively

related to insulin sensitivity $[6,11,13,14]$. Most studies report whole cell DAG content, yet there are a large number of potential molecular species of DAG, as well as variability in intracellular localisation that could influence biological action. We hypothesised that both membrane DAG localisation and saturated molecular species would be independently related to skeletal muscle insulin action. Indeed, major findings from the present study confirm our hypotheses. Of the 16 measurable molecular species of DAG in human skeletal muscle, the majority are localised to membranes, and only membrane DAG were positively related to PKC activation and insulin resistance. Three particular species of DAG were significantly higher in individuals with type 2 diabetes than the other groups, but only di-C18:0 was significantly related to insulin resistance. Decreasing DAG localised to skeletal muscle membranes, or decreasing stearate-containing DAG may be a novel therapeutic target for the treatment and prevention of insulin resistance in humans.

Currently, all DAG in human skeletal muscle is thought to promote insulin resistance. Consistent with previous investigations, total intramuscular DAG concentration correlated inversely with insulin sensitivity in this study. Nevertheless, because DAG induces insulin resistance by activating PKC in membranes, we hypothesised that only membrane DAG would be related to PKC activation and insulin resistance in skeletal muscle. Supportive data were reported in a recent study demonstrating increased skeletal muscle membrane DAG content during ageing, which was associated with increased PKC activation and insulin resistance in rodents [17]. Similarly, liver samples from morbidly obese participants also revealed compartmentalisation of DAG, with cytosolic, but not membrane, DAG correlated with PKC $\varepsilon$ activation [23]. Our data show the importance of DAG compartmentalisation in human skeletal muscle, as only membrane DAG was related to PKC activation and decreased insulin sensitivity. In contrast, cytosolic DAG was inversely related to insulin resistance and $\mathrm{PKC} \varepsilon$ activation. Together, these data are the first to reveal that membrane localisation of DAG in skeletal muscle, rather than total intramuscular concentration, drives insulin resistance in humans.

Alterations in DAG production induced by obesity and/or type 2 diabetes may explain differences in DAG localisation. For example, hyperglycaemia increases phospholipase $\mathrm{C}$ activity [24], which degrades membrane phospholipids and would produce membrane DAG. Increased C18:0/C20:4 DAG in type 2 diabetes is consistent with phospholipase DAG generation. Hyperinsulinaemia and hyperglycaemia also increase de novo DAG synthesis [25], which occurs at the endoplasmic reticulum [26], and could be an important mechanism promoting membrane DAG accumulation in obesity and diabetes. In contrast, DAG formed during IMTG degradation [27] would promote cytosolic accumulation and may be less prominent in type 2 diabetes. The combination of enhanced de novo DAG 
Fig. 6 Relationship between $\mathrm{PKC} \varepsilon$ activation and cytosolic DAG $(r=-0.552, p=0.009)($ a) and membrane DAG $(r=0.507$, $p=0.019)(\mathbf{b})$ in T2D, Ath and $\mathrm{Ob}$ groups
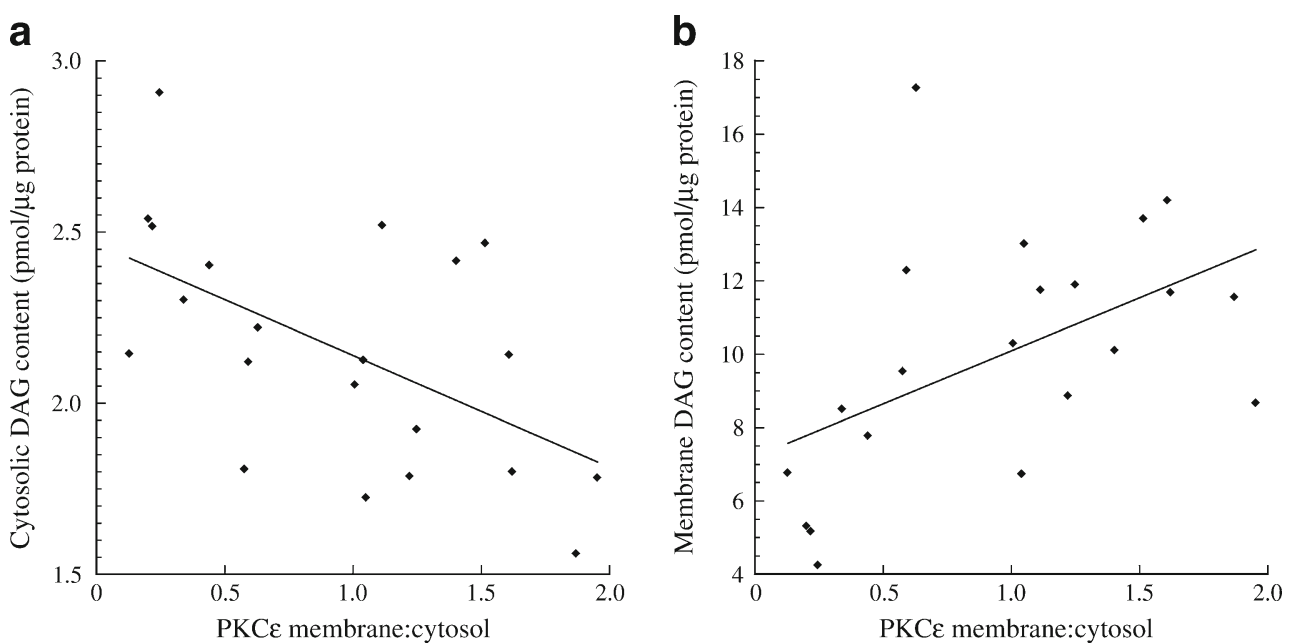

synthesis driven by elevated plasma concentrations of glucose and insulin, high saturated fat intake [28], and less muscle lipid desaturation form a plausible explanation for how saturated membrane DAG accumulate in obesity and diabetes. Exploiting pathways dictating intracellular DAG localisation may prove a novel target for insulin sensitisation.
Whether decreasing membrane DAG increases insulin sensitivity is not known, but would be supported by these data. Altered abundance of DGK $\delta$, an enzyme responsible for converting DAG into phosphatidic acid to terminate DAG signalling [29], may be one manner of doing so. DGK $\delta$ exists in many locations of the cell, including endoplasmic reticulum
Fig. 7 a Content of disaturated DAG in membrane fraction in T2D, Ath and Ob groups. b Relationship between disaturated membrane DAG and insulin sensitivity $(\mathrm{Si})$ $(r=-0.642, p=0.002)$ c Percentage of disaturated DAG relative to total membrane DAG. d Relationship between percentage disaturated DAG relative to total membrane DAG and $\mathrm{Si}(r=-0.633, p=0.002)$ To convert Si values to SI units multiply by 0.167 . Significantly different from $\mathrm{Ob},{ }^{*} p<0.05$; significantly different from $\mathrm{T} 2 \mathrm{D},{ }^{\dagger} p<0.05$. T2D, type 2 diabetes
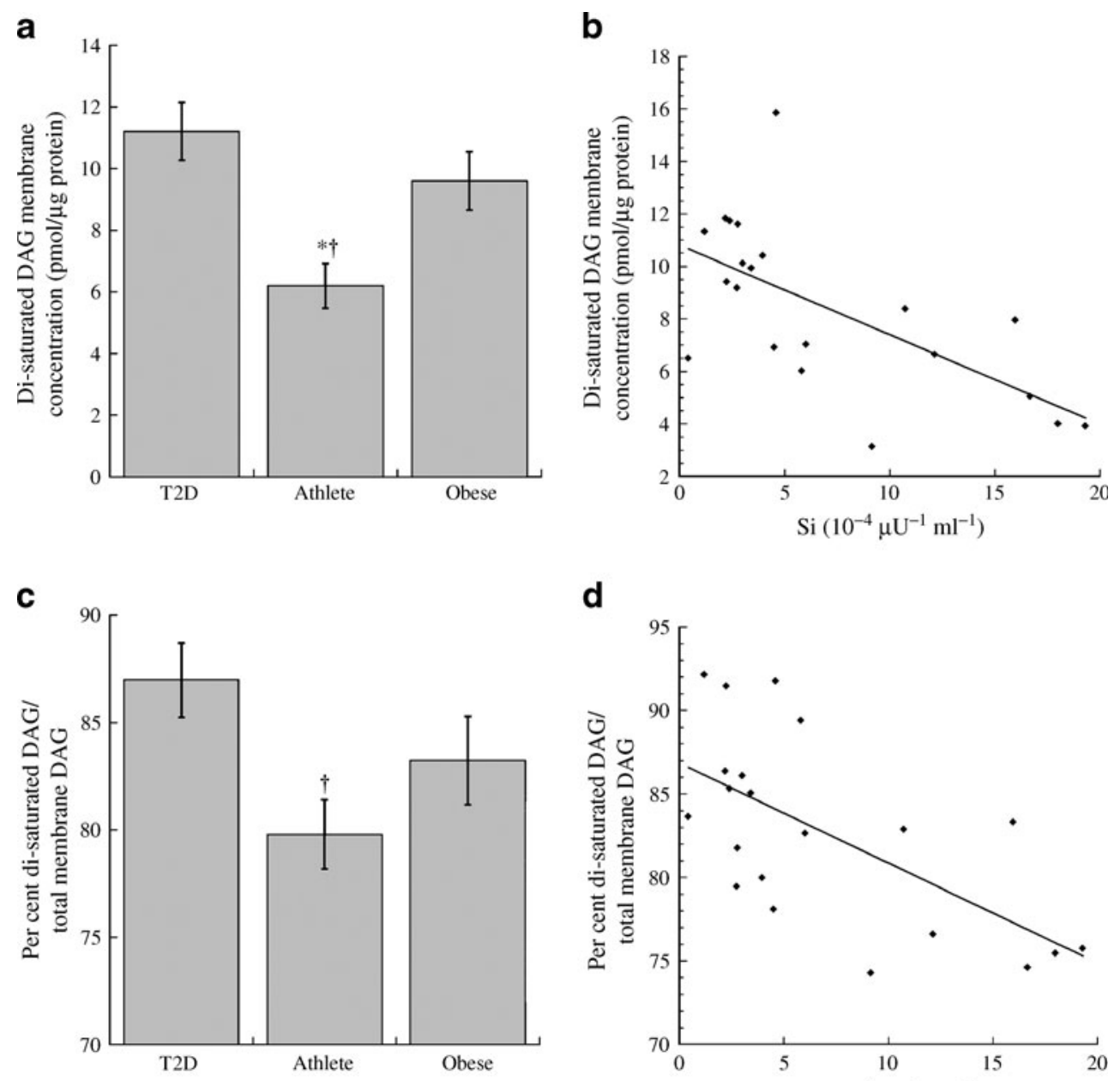

d

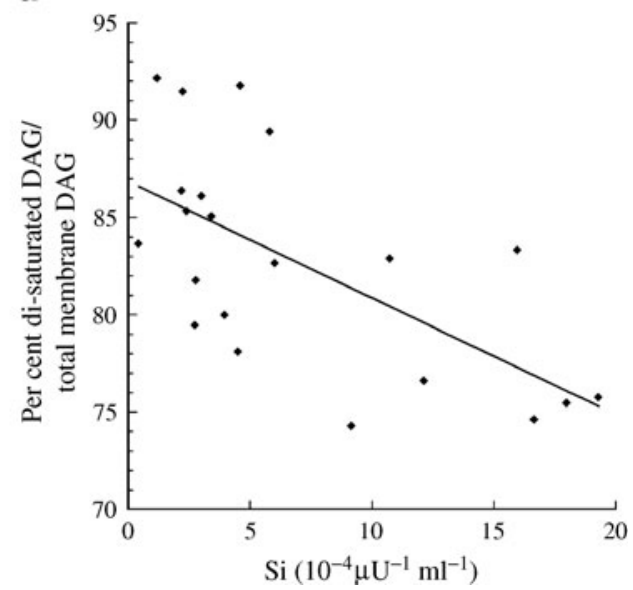


a

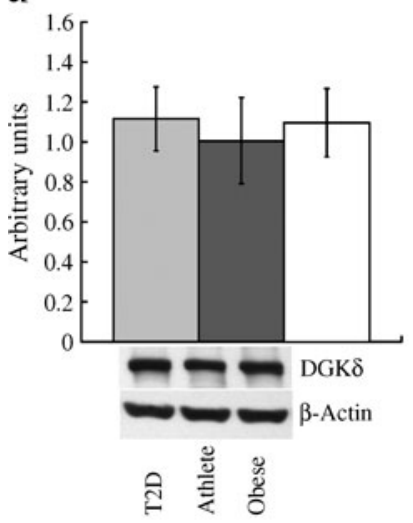

C

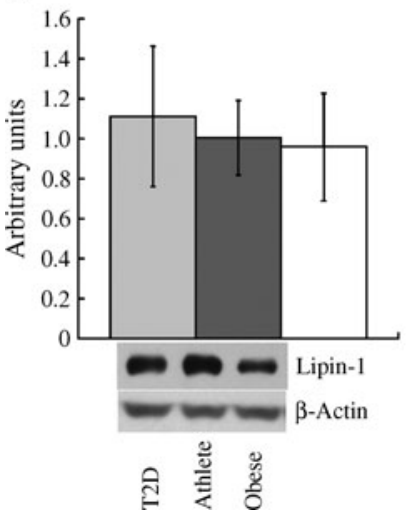

b

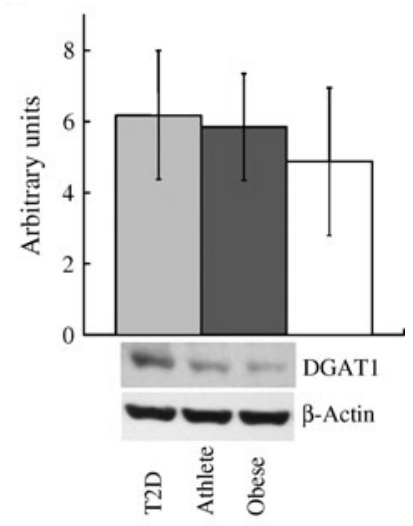

d

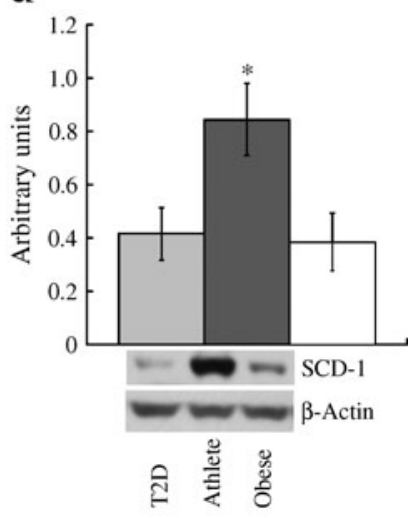

Fig. 8 Skeletal muscle protein levels of DGK $\delta$ (a), DGAT1 (b), lipin 1 (c) and SCD1 (d) in T2D (light grey), Ath (dark grey) and Ob (white) groups. Values are means \pm SEM. Significantly different from $\mathrm{Ob},{ }^{*} p<$ 0.05 . T2D, type 2 diabetes

[30], neuromuscular junction [31], cytoskeletal compartments [32] and the nucleus, which confirms intracellular DAG compartmentalisation [29]. In a previous study, hyperglycaemia downregulated DGK $\delta$ and explained increased DAG concentration in individuals with type 2 diabetes [33]. We found no differences in whole cell DGK $\delta$ between groups, suggesting that changes in DAG content and/or localisation was not due to downregulation of this enzyme. Of note, hyperglycaemia in our participants with type 2 diabetes was $\sim 2.2 \mathrm{mmol} / \mathrm{l}$ lower than in the previous report, and may contribute to the lack of differences in this study. Membrane DAG content may also be influenced by muscle oxidative capacity. Preventing mitochondrial oxidative damage preserved oxidative capacity and precluded membrane DAG accumulation and insulin resistance in ageing mice [17]. Similarly, muscle oxidative capacity is increased in endurance-trained athletes, who also had decreased membrane DAG content in the present study. These studies suggest a possible link between oxidative capacity, membrane DAG localisation and insulin sensitivity. Nevertheless, further studies are needed to determine if membrane DAG content can be decreased, and if this change results in increased insulin sensitivity.

In addition to DAG localisation, DAG composition appears to discriminate DAG function, and therefore plays an important role linking muscle lipids to insulin resistance. Of the 16 measurable membrane DAG species, only di-C18:0 was significantly related to insulin sensitivity. Interestingly, these data corroborate previous data from our laboratory and others suggesting that saturated DAG has a particularly negative impact on insulin sensitivity $[4,5,7]$. This is exemplified by the observation that disaturated membrane DAGs were negatively related to insulin sensitivity in the cohort as a whole, and were also significantly lower in our insulin-sensitive endurancetrained athletes. Similar to other reports [5], SCD1 content was increased in athletes, which may be one mechanism explaining less saturated skeletal muscle DAG in this group. Less saturated membrane DAG in endurance-trained athletes may help explain how they maintain insulin sensitivity, despite a high IMTG concentration, the so-called 'athletes paradox' [34]. Further, these data highlight that DAG species are not homogeneous and probably have dissimilar impacts on insulin sensitivity. Similar data showing that unique DAG species correlated with PKC activation and insulin sensitivity were recently reported in human liver [23]. However, not all data agree, as two recent studies $[10,35]$ did not observe the relationship between skeletal muscle DAG molecular species and insulin sensitivity observed in the present study. This apparent discrepancy can be reconciled when considering that the relative importance of DAG species differs by their subcellular location. Similar to the data of Coen et al. [10] and Dube et al. [35], we also did not find a significant relationship between insulin sensitivity and individual DAG species when DAG species from the whole cell were analysed. However, when only membrane species were examined, the relationship between di-C18:0 DAG and insulin sensitivity was revealed. Therefore our data agree with previous studies in this area, but, importantly, extend what is known, highlighting the importance of DAG based on location and species.

DAG is thought to decrease insulin sensitivity in skeletal muscle by promoting activity of conventional and novel PKC isoforms [11, 14]. Localisation of DAG species was important for PKC activation, as C16:1/C18:1 was positively related to $\mathrm{PKC} \varepsilon$ activation in the membrane, with no relationship in the cytosol. The prevailing paradigm would contend that polyunsaturated fatty acid-containing DAG activate PKC $[36,37]$; however, the literature contains reports suggesting that saturated DAGs are related to PKC activation as well [16, 38, 39]. Nevertheless, we found no significant relationships between polyunsaturated fatty acid containing-DAG and $\mathrm{PKC} \theta$ and $\mathrm{PKC} \varepsilon$ activation, but rather an effect of monounsaturated fatty acid containing-DAG in the membrane on $\mathrm{PKC} \varepsilon$. Divergence between membrane DAG molecular species related to insulin sensitivity and PKC activation may be due to involvement of PKC isoforms PKCßII and PKC $\delta$, which we did not measure [14], and/or implicate non-PKC- 
mediated mechanisms for the effect of DAG on insulin resistance in humans [40]. Alternatively, while there are data suggesting that PKC isoforms are involved in acute insulin resistance $[14,15,41-43]$, other data suggest that they may not be related to chronic insulin resistance [44-46]. Our data can also be interpreted as placing less importance on DAG-induced PKC activation in chronic insulin resistance in humans. These data are also consistent with the interpretation that saturated DAG are only a marker of insulin resistance, and may reflect increased saturated lipid content of other species, such as ceramides $[9,10]$ and/or long-chain acyl-CoA [8], which may play a more direct role.

There are several limitations to this study. It is well known that dietary fat influences muscle lipid composition [47], and a recent study showed that a 1-week dietary intervention changed the composition of DAG in healthy lean men and women [28]. Therefore our 3-day dietary control, designed to ensure energy balance, may have minimised differences between groups. Although others have reported PKC activation using membrane/cytosol ratios [15, $21,48]$, variability between participants and a small sample size in this study may have precluded finding relationships that exist between PKC isoforms and DAG species. We did not have a lean control group, which does not allow us to discern the influence of BMI from exercise training when comparing athletes with the other two groups. In addition, skeletal muscle was only separated into two fractions. Therefore alterations in DAG localised to endoplasmic reticulum from de novo synthesis cannot be delineated from plasma membrane DAG with our methods. Owing to the hydrophobic nature of DAG, the cytosolic fraction may also not truly represent 'cytosolic' distribution, but rather DAG localised to small membrane structures or in cytosolic lipid droplets pelleting during the first centrifugation step. In addition, we measured insulin sensitivity using an IVGTT, which does not isolate the influence of muscle on insulin sensitivity as well as a hyperinsulinaemic/euglycaemic clamp. Further, we are assuming that DAG promotes insulin resistance by binding to C1-containing domains of PKC [40]. However, other molecules with $\mathrm{C} 1$-containing domains may be stimulated by DAG, including chimaerins, protein kinase D, ras guanyl nucleotide-releasing proteins (RasGRPs), mammalian homologues of $C$. elegans Unc-13 (Munc13s) and DAG kinase $\gamma[40]$.

In summary, these data are the first report of cellular localisation of molecular species of DAG in human skeletal muscle. Together, they challenge the existing paradigm that all DAG species negatively impact insulin action in skeletal muscle. Only membrane, not cytosolic, DAG were found to be related to insulin resistance in the present study. Further, this relationship was largely driven by the amount of di-C18:0 DAG. Therefore therapeutic strategies to alter DAG composition and/or decrease membrane DAG localisation may be a novel target to promote insulin sensitivity in humans.

Funding This work was partially supported by the National Institutes of Health General Clinical Research Center (grant RR-00036) and National Institute of Diabetes and Digestive and Kidney Diseases (NIDDK) (grants to L. Perreault [DK-064811] and B.C. Bergman [DK-059739 and R01DK089170]).

Duality of interest The authors declare that there is no duality of interest associated with this manuscript.

Contribution statement $\mathrm{BCB}$ designed the study, performed participant testing, analysed data, and wrote the manuscript. DMH performed participant testing, analysed samples, interpreted data and edited the manuscript. AK performed participant testing, analysed samples, interpreted data and edited the manuscript. MCP performed participant testing, analysed samples, interpreted data, and edited the manuscript. LP helped design the study, provided medical oversight, performed all biopsies, and helped write the manuscript. All authors approved the final manuscript prior to publication.

\section{References}

1. DeFronzo RA, Ferrannini E, Hendler R, Felig P, Wahren J (1983) Regulation of splanchnic and peripheral glucose uptake by insulin and hyperglycemia in man. Diabetes 32:35-45

2. Liu L, Zhang Y, Chen N, Shi X, Tsang B, Yu YH (2007) Upregulation of myocellular DGAT1 augments triglyceride synthesis in skeletal muscle and protects against fat-induced insulin resistance. J Clin Investig 117:1679-1689

3. Schenk S, Horowitz JF (2007) Acute exercise increases triglyceride synthesis in skeletal muscle and prevents fatty acid-induced insulin resistance. J Clin Investig 117:1690-1698

4. Bergman BC, Perreault L, Hunerdosse DM, Koehler MC, Samek AM, Eckel RH (2009) Intramuscular lipid metabolism in the insulin resistance of smoking. Diabetes 58:2220-2227

5. Bergman BC, Perreault L, Hunerdosse DM, Koehler MC, Samek AM, Eckel RH (2010) Increased intramuscular lipid synthesis and low saturation relate to insulin sensitivity in endurance-trained athletes. J Appl Physiol 108:1134-1141

6. Bruce CR, Thrush AB, Mertz VA et al (2006) Endurance training in obese humans improves glucose tolerance and mitochondrial fatty acid oxidation and alters muscle lipid content. Am J Physiol Endocrinol Metab 291:E99-E107

7. van Hees AM, Jans A, Hul GB, Roche HM, Saris WH, Blaak EE (2011) Skeletal muscle fatty acid handling in insulin resistant men. Obesity 19:1350-1359

8. Houmard JA, Tanner CJ, Yu C et al (2002) Effect of weight loss on insulin sensitivity and intramuscular long-chain fatty acyl-CoAs in morbidly obese subjects. Diabetes 51:2959-2963

9. Holland WL, Brozinick JT, Wang LP et al (2007) Inhibition of ceramide synthesis ameliorates glucocorticoid-, saturated-fat-, and obesity-induced insulin resistance. Cell Metab 5:167-179

10. Coen PM, Dube JJ, Amati F et al (2010) Insulin resistance is associated with higher intramyocellular triglycerides in type I but not type II myocytes concomitant with higher ceramide content. Diabetes 59:80-88

11. Schmitz-Peiffer C, Browne CL, Oakes ND et al (1997) Alterations in the expression and cellular localization of protein kinase $\mathrm{C}$ 
isozymes epsilon and theta are associated with insulin resistance in skeletal muscle of the high-fat-fed rat. Diabetes 46:169-178

12. Avignon A, Yamada K, Zhou X et al (1996) Chronic activation of protein kinase $\mathrm{C}$ in soleus muscles and other tissues of insulinresistant type II diabetic Goto-Kakizaki (GK), obese/aged, and obese/Zucker rats. A mechanism for inhibiting glycogen synthesis. Diabetes 45:1396-1404

13. Heydrick SJ, Ruderman NB, Kurowski TG, Adams HB, Chen KS (1991) Enhanced stimulation of diacylglycerol and lipid synthesis by insulin in denervated muscle. Altered protein kinase $\mathrm{C}$ activity and possible link to insulin resistance. Diabetes 40:1707-1711

14. Itani SI, Ruderman NB, Schmieder F, Boden G (2002) Lipidinduced insulin resistance in human muscle is associated with changes in diacylglycerol, protein kinase C, and IkappaB-alpha. Diabetes 51:2005-2011

15. Griffin ME, Marcucci MJ, Cline GW et al (1999) Free fatty acidinduced insulin resistance is associated with activation of protein kinase $\mathrm{C}$ theta and alterations in the insulin signaling cascade. Diabetes 48:1270-1274

16. Montell E, Turini M, Marotta M et al (2001) DAG accumulation from saturated fatty acids desensitizes insulin stimulation of glucose uptake in muscle cells. Am J Physiol Endocrinol Metab 280: E229-E237

17. Lee HY, Choi CS, Birkenfeld AL et al (2010) Targeted expression of catalase to mitochondria prevents age-associated reductions in mitochondrial function and insulin resistance. Cell Metab 12:668-674

18. Boston RC, Stefanovski D, Moate PJ, Sumner AE, Watanabe RM, Bergman RN (2003) MINMOD Millennium: a computer program to calculate glucose effectiveness and insulin sensitivity from the frequently sampled intravenous glucose tolerance test. Diabetes Technol Ther 5:1003-1015

19. Guo Z, Mishra P, Macura S (2001) Sampling the intramyocellular triglycerides from skeletal muscle. J Lipid Res 42:1041-1048

20. Bielawski J, Szulc ZM, Hannun YA, Bielawska A (2006) Simultaneous quantitative analysis of bioactive sphingolipids by highperformance liquid chromatography-tandem mass spectrometry. Methods 39:82-91

21. Schmitz-Peiffer C, Biden TJ (2008) Protein kinase C function in muscle, liver, and beta-cells and its therapeutic implications for type 2 diabetes. Diabetes 57:1774-1783

22. Moro C, Galgani JE, Luu L et al (2009) Influence of gender, obesity, and muscle lipase activity on intramyocellular lipids in sedentary individuals. J Clin Endocrinol Metab 94:34403447

23. Kumashiro N, Erion DM, Zhang D et al (2011) Cellular mechanism of insulin resistance in nonalcoholic fatty liver disease. Proc Natl Acad Sci U S A 108:16381-16385

24. Yasunari K, Kohno M, Kano H, Yokokawa K, Horio T, Yoshikawa J (1996) Possible involvement of phospholipase D and protein kinase $\mathrm{C}$ in vascular growth induced by elevated glucose concentration. Hypertension 28:159-168

25. Xia P, Inoguchi T, Kern TS, Engerman RL, Oates PJ, King GL (1994) Characterization of the mechanism for the chronic activation of diacylglycerol-protein kinase $\mathrm{C}$ pathway in diabetes and hypergalactosemia. Diabetes 43:1122-1129

26. Hodgkin MN, Pettitt TR, Martin A, Michell RH, Pemberton AJ, Wakelam MJ (1998) Diacylglycerols and phosphatidates: which molecular species are intracellular messengers? Trends Biochem Sci 23:200-204

27. Timmers S, Schrauwen P, de Vogel J (2008) Muscular diacylglycerol metabolism and insulin resistance. Physiol Behav 94: 242-251

28. Kien CL, Everingham KI, Stevens RD, Fukagawa NK, Muoio DM (2011) Short-term effects of dietary fatty acids on muscle lipid composition and serum acylcarnitine profile in human subjects. Obesity 19:305-311
29. Luo B, Regier DS, Prescott SM, Topham MK (2004) Diacylglycerol kinases. Cell Signal 16:983-989

30. Nagaya H, Wada I, Jia YJ, Kanoh H (2002) Diacylglycerol kinase delta suppresses ER-to-Golgi traffic via its SAM and PH domains. Mol Biol Cell 13:302-316

31. Abramovici H, Hogan AB, Obagi C, Topham MK, Gee SH (2003) Diacylglycerol kinase-zeta localization in skeletal muscle is regulated by phosphorylation and interaction with syntrophins. Mol Biol Cell 14:4499-4511

32. Tolias KF, Couvillon AD, Cantley LC, Carpenter CL (1998) Characterization of a Rac1- and RhoGDI-associated lipid kinase signaling complex. Mol Cell Biol 18:762-770

33. Chibalin AV, Leng Y, Vieira E et al (2008) Downregulation of diacylglycerol kinase delta contributes to hyperglycemia-induced insulin resistance. Cell 132:375-386

34. Goodpaster BH, He J, Watkins S, Kelley DE (2001) Skeletal muscle lipid content and insulin resistance: evidence for a paradox in endurance-trained athletes. J Clin Endocrinol Metab $86: 5755-5761$

35. Dube JJ, Amati F, Toledo FG et al (2011) Effects of weight loss and exercise on insulin resistance, and intramyocellular triacylglycerol, diacylglycerol and ceramide. Diabetologia 54: $1147-1156$

36. Wakelam MJ (1998) Diacylglycerol: when is it an intracellular messenger? Biochim Biophys Acta 1436:117-126

37. Hinderliter AK, Dibble AR, Biltonen RL, Sando JJ (1997) Activation of protein kinase $\mathrm{C}$ by coexisting diacylglycerolenriched and diacylglycerol-poor lipid domains. Biochemistry 36:6141-6148

38. Inoguchi T, Li P, Umeda F et al (2000) High glucose level and free fatty acid stimulate reactive oxygen species production through protein kinase $\mathrm{C}$-dependent activation of $\mathrm{NAD}(\mathrm{P}) \mathrm{H}$ oxidase in cultured vascular cells. Diabetes 49:1939-1945

39. Yu HY, Inoguchi T, Kakimoto $M$ et al (2001) Saturated nonesterified fatty acids stimulate de novo diacylglycerol synthesis and protein kinase $\mathrm{c}$ activity in cultured aortic smooth muscle cells. Diabetologia 44:614-620

40. Brose N, Rosenmund C (2002) Move over protein kinase C, you've got company: alternative cellular effectors of diacylglycerol and phorbol esters. J Cell Sci 115:4399-4411

41. Kim JK, Fillmore JJ, Sunshine MJ et al (2004) PKC-theta knockout mice are protected from fat-induced insulin resistance. J Clin Investig 114:823-827

42. Raddatz K, Turner N, Frangioudakis G et al (2011) Timedependent effects of Prkce deletion on glucose homeostasis and hepatic lipid metabolism on dietary lipid oversupply in mice. Diabetologia 54:1447-1456

43. Samuel VT, Liu ZX, Wang A et al (2007) Inhibition of protein kinase Cepsilon prevents hepatic insulin resistance in nonalcoholic fatty liver disease. J Clin Investig 117:739-745

44. Serra C, Federici M, Buongiorno A et al (2003) Transgenic mice with dominant negative PKC-theta in skeletal muscle: a new model of insulin resistance and obesity. J Cell Physiol 196:89-97

45. Gao Z, Wang Z, Zhang X et al (2007) Inactivation of PKCtheta leads to increased susceptibility to obesity and dietary insulin resistance in mice. Am J Physiol Endocrinol Metab 292: E84-E91

46. Schmitz-Peiffer C, Laybutt DR, Burchfield JG et al (2007) Inhibition of PKCepsilon improves glucose-stimulated insulin secretion and reduces insulin clearance. Cell Metab 6:320-328

47. Andersson A, Nalsen C, Tengblad S, Vessby B (2002) Fatty acid composition of skeletal muscle reflects dietary fat composition in humans. Am J Clin Nutr 76:1222-1229

48. Itani SI, Zhou Q, Pories WJ, MacDonald KG, Dohm GL (2000) Involvement of protein kinase $\mathrm{C}$ in human skeletal muscle insulin resistance and obesity. Diabetes 49:1353-1358 